\title{
Virtual reality and stimulation of touch and smell for inducing relaxation: A randomized controlled trial
}

\author{
Berenice Serrano $^{\mathrm{a}, \mathrm{c}}$, Rosa M. Baños ${ }^{\mathrm{b}, \mathrm{c}}$, and Cristina Botella ${ }^{\mathrm{a}, \mathrm{c}}$ \\ ${ }^{a}$ Universitat Jaume I, Castellón de la Plana, 12071, Spain \\ ${ }^{\mathrm{b}}$ Universitat de Valencia, Valencia, 46010, Spain \\ ${ }^{\text {c} C I B E R ~ F i s i o p a t o l o g i ́ a, ~ O b e s i d a d ~ y ~ N u t r i c i o ́ n, ~ I n s t i t u t o ~ S a l u d ~ C a r l o s ~ I I I, ~ G i r o n a, ~ S p a i n ~}$
}

\begin{abstract}
The aim of this study was to test the efficacy of a mood-induction procedure in a Virtual Reality (VR-MIP) environment for inducing relaxation and generating sense of presence, and to test whether the stimulation of the senses of touch and smell improves the efficacy of this VR-MIP. A controlled study was carried out with four experimental conditions. All of them included the VRMIP to induce relaxation, but varying the senses stimulated. The sample consisted of 136 participants randomly assigned to one of the four experimental conditions. Emotions and sense of presence were evaluated. The results showed statistical differences before and after mood-induction and a high sense of presence in all groups. However, no statistical differences were found among the four groups on emotions and sense of presence. The results showed that the VR-MIP was effective; however, the stimulation of the senses of touch and smell did not show significate improve of the mood-induction or the sense of presence. It was identified a trend in favor of the groups where the sense of touch was stimulated, they seemed more relaxed and the sense of presence was higher. We hypothesized that the stimulation of sense of touch, could improve the efficacy when using VR-MIP because it provides more sensory information.
\end{abstract}

Keywords: Virtual reality; Mood-induction; Relaxation; Touch; Smell; Augmented virtuality 


\section{Introduction}

Virtual Reality (VR) allows the simulation of real-life situations in a tridimensional computergenerated environment where the user can interact with the environment as if he/she were in the real world. In VR it is possible to interact in real time with different objects and experience a sense of presence, -the illusion of "being there"- (Baños, Botella, \& Perpiñá, 1999). Since its emergence, VR has diversified its application areas, with the most common being: architectural design, useroriented design, marketing, military training, surgery simulation, medical training, education, physical rehabilitation, and psychological treatments.

This technology enables users to interact and immerse themselves in an environment through the stimulation of different senses. In 1957, Morton Heilig designed the first approximation of a virtual environment (VE) to stimulate various senses. This system was called "Sensorama", and it consisted of a display enriched with objects from the physical world (e.g., images, sounds, odors). It tried to provide the illusion of reality by using a 3D motion picture with smell, stereo sound, and seat vibration, or increasing the sense of movement by blowing air into users' faces. Despite this initial system, the most common senses stimulated in VE have been sight (using 3D images) and hearing (using computer-generated sounds). In recent years, the possibility of using strategies to stimulate smell, touch or taste has been considered, with the purpose of improving sensory experiences in VE. For instance, Dinh, Walker, Hodges, Song, and Kobayashi (1999) analyzed the possibility of stimulating different senses in order to enhance the VR experience. They evaluated the effects of smell, touch, sight and hearing on the sense of presence and memory. They used stimuli associated with specific objects in the VE (scent of coffee for smell, specific sounds for hearing, a real fan to provoke the sensation of air on the participants' skin, or a light lamp to produce the feeling of the sun on the skin to stimulate touch). Their results showed that the more senses stimulated, the higher the sense of presence, specifically when hearing and touch were introduced. Hoffman, Hollander, Schroder, Rousseau, and Furness (1998) also found evidence of the role of tactile sensations. In their study, participants could interact with physical objects by 
means of tactile augmentation. While a virtual hand was exploring a virtual object, the real hand was exploring the real object at the same time. The authors suggest that adding physical objects that provide tactile feedback for actions increases the sense of presence in VEs. Other studies have focused on olfactory stimulation. For example, Tortell et al. (2007) associated scents with specific objects in a VE to assess their influence on memory.

Other studies used tactile or olfactory stimuli with the specific purpose of improving the sense of presence in VEs in the treatment of specific phobias (Carlin, Hoffman, \& Weghorst, 1997; Hoffman, García-Palacios, Carlin, Furness, \& Botella, 2003) or posttraumatic stress disorder (Rizzo et al., 2010; Rothbaum, Rizzo, \& Difede, 2010), and they concluded that by adding other sense stimuli, the effectiveness of VR exposure therapy for the phobia increased.

One of the applications of VE in the field of psychology has been to induce various moods and emotions, as a "mood-induction procedure" (VR-MIP). For instance, (Baños et al., 2013) used VEs to induce positive emotions (joy and relaxation) in a specific population (adult hospitalized patients with metastatic cancer). The participants used the VR-MIP in four sessions lasting 30 minutes each for one week. Results showed an increase in positive emotions and a decrease in negative emotions (sadness and anxiety). In a recent pilot study (Baños et al., 2014), participants (pre-graduate students) received a VR-MIP to induce relaxation and joy in six sessions over a period of two weeks. Results showed an improvement in joy and relaxation after using the VR-MIP. Another recent study (Herrero, García-Palacios, Castilla, Molinari, \& Botella, 2014) evaluated the efficacy of using a VR-MIP (in a group session) to induce positive emotions in patients with fibromyalgia syndrome as a component of their psychological treatment. Results showed significant increases in positive emotions (joy, surprise, calmness, and vigor), as well as in motivation and self-efficacy. Several studies have found that the use of emotional VE helps to increase the sense of presence. For instance, Baños et al. (2004b) studied the effectiveness of a VE (a virtual park) in inducing sadness, joy, relaxation and anxiety, and they concluded that emotional VE increased the participants' sense of presence compared to non-emotional (neutral) VE. In a further study, Baños et al. (2008) found a 
relationship between the intensity of positive emotions (relaxation and joy) and a strong sense of presence. Riva et al. (2007) also used VE to induce relaxation and anxiety, and their results also confirm the bidirectional relationship between emotions and sense of presence.

However, although there is evidence of the use of VE to induce emotions, and of the relationship between emotions and sense of presence, all of these studies used only sight and hearing stimuli. In fact, as mentioned above, research in VR using other senses such as touch or smell is very limited, even though some studies have emphasized the importance of improving VR experiences and suggested that including other stimuli (e.g. olfactory) could produce more immersive experiences, as long as the stimuli are consistent with the VE (Tortell et al., 2007). Other studies have proposed that using olfactory stimuli in VE could evoke certain emotions, which would have a direct impact on behavior (Baus \& Bouchard, 2010). Along these lines, a recent review (Aiken \& Berry, 2015) highlights the potential role of olfactory stimuli for improving VR exposure therapy, especially in the treatment of posttraumatic stress disorder, as smell can influence emotion and affective response, facilitate recall, or increase sense of presence.

We developed and tested a VR-MIP (“House of Relaxation") in a pilot study, and the results showed that it was effective in inducing relaxation and sense of presence (Serrano, Botella, Baños, \& Alcañiz, 2013). However, this non controlled study had several limitations, such as the small number of participants and the fact that only two senses (sight and hearing) were stimulated. The present study tries to advance in this line of research by using the same VR-MIP ("House of Relaxation") along with the stimulation of the senses of sight, hearing, touch, and smell. The possibilities of VR for inducing emotions and its efficacy demonstrated in several studies is first introduced and motivated. In addition the possibility of improving these mood-inductions with the stimulation of the senses of touch and smell is exposed. Then, the main objectives and hypotheses to be evaluated in this study are specified. Subsequently the details of the experiment to test the hypothesis are described; including participant characteristics, the description of the measures, the specifications of the VR environment and tactile and olfactory stimuli, and the details 
of the procedure that guided the experiment. Next, the results found are described, and finally the conclusions and limitations found are exposed, as well as the recommendations for future studies in this research are specified.

The main objectives of this study are to test, in a controlled study, the efficacy of this VR-MIP to induce relaxation and sense of presence, and to analyze whether the stimulation of the senses of touch and smell improves the efficacy of this VR-MIP in inducing relaxation and sense of presence. The following hypotheses are tested:

H1: The relaxation scores will increase significantly in participants after the VR-MIP.

$\mathrm{H} 2$ : The stimulation of the senses of touch and smell will enhance the relaxation experience.

Statistically significant differences between groups will be observed in this direction: the groups in which these senses were stimulated will be more relaxed.

H3: Participants will report a high sense of presence after the VR-MIP.

H4: The stimulation of the senses of touch and smell will enhance the sense of presence.

Statistically significant differences between groups will be observed. It is expected that the groups in which these senses were stimulated will experience a greater sense of presence.

\section{Material and methods}

\subsection{Participants}

The sample was composed of 136 participants ( 84 women and 52 men) whose ages ranged from 18 to 63 years $(M=27.05, \mathrm{SD}=8.01)$. Participants were recruited using different strategies, and they received a financial reward of $12 €$. The inclusion criteria were: being between 18 and 65 years old and not having any clinical symptoms of anxiety and/or depression. All the participants were evaluated using first a Clinical Assessment Questionnaire designed for this study, and then the Beck Depression Inventory II (Sanz, Perdigón, \& Vázquez, 2003) and the State-Trait Anxiety Inventory (Spielberger, Gorsuch, \& Lushene, 1986) to identify clinical symptoms. Participants were allocated to each of the four experimental groups by the Random Allocation Software (Saghaei, 2004). 


\subsection{Measures}

Clinical Assessment Questionnaire. It is a brief 12-item questionnaire developed specifically for this research; its aim was to identify anxiety and/or depression symptoms in order to decide if it was necessary to perform a more specific assessment of depression and anxiety.

Beck Depression Inventory II: BDI-II [(Beck, Steer, \& Brown, 1996), Spanish validation by Sanz et al. (2003)] . It is a measure containing 21-self-report items on depressive symptoms. BDI is the most widely used instrument for assessing the severity of depressive symptoms in the clinical and research fields. The Spanish validation shows a high internal consistency (0.87) and consistently produces the same result.

State-Trait Anxiety Inventory: STAI (Spielberger et al., 1986). It is a self-report measure that assesses the trait and state anxiety levels. The inventory has two scales with 20 items each, half of them written positively and half negatively. Participants rate on a 4-point Likert scale how they feel at that moment (State scale), or how they feel generally (Trait scale). Its internal consistency reliability was 0.90 for the State scale and 0.93 for the Trait scale. In this study, we use only the State scale.

Visual Analogue Scale: VAS (Gross \& Levenson, 1995; Wewers \& Lowe, 1990). This is a subjective and self-administered measure with a $10 \mathrm{~cm}$ line where the intensity of the emotional state is indicated. Four VAS were used to evaluate sadness, joy, anxiety, and relaxation moods. Participants were asked to rate how strongly they were experiencing each of the emotions evaluated at that moment on a $0-10$ point Likert scale $(0=$ not feeling the emotion at all, $10=$ feeling the emotion very strongly).

Self-Assessment Manikin: SAM [(Bradley \& Lang, 1994), Spanish validation by Moltó et al. (1999) and Vila et al. (2001)]. This measure is a non-verbal pictorial-assessment technique that directly measures the affective valence, arousal, and dominance associated with a person's affective reaction to a stimuli. Participants represent their affective valence by choosing between happy and unhappy figures. Excited or relaxed figures represent the arousal dimension; the dominance 
dimension represents changes in control with changes in the size of figures (i.e., a large figure indicates maximum control in the situation). Participants could select any of the five figures on each scale or between any two figures, which resulted in a 9-point Likert scale for each dimension. In the validation study, the correlation was high for the affective valence $(r=0.97)$ and arousal $(r=0.94)$; the dominance correlation was not significant. In this study, we did not use the dominance dimension.

Presence Self-Assessment Manikin: Presence-SAM (Schneider, Lang, Shin, \& Bradley, 2004). This is a 9-point pictorial scale adapted from the SAM measure (Bradley \& Lang, 1994). The authors designed the scale to be moderately correlated $(r=0.50)$ with a verbal sense of presence scale. A further study by Wissmath, Weibel, and Mast (2009) found that this measure involved less effort for participants and measured sense of presence more directly than a verbal measurement $[(M=2.10$; $\mathrm{SD}=0.98), \mathrm{F}(1,158)=9.60, p<0.01)]$. This measure was selected because it is short, simple and fast.

\subsection{Virtual reality environment}

The VR environment simulated a two-story house located in a meadow and called the "House of Relaxation" (Figure 1). In it, the following MIP for inducing relaxation were included: affective pictures from the International Affective Pictures System (Ito, Cacioppo, \& Lang, 1998), Velten’s self-statements (Velten, 1968), a video-clip with a relaxing scene, relaxing music and narratives, sounds of nature, and autobiographical recalls. In addition, in the House of Relaxation, users can perform different actions: modifying the pictures and the self-statements (they were included as part of the house decor); watching a video-clip; changing the intensity of the lights; opening or closing doors and windows; moving up or down stairs; moving or adding furniture; changing the color of the walls; changing the floor into grass or sand; or changing the exterior landscape to reflect another natural context (beach or snow). For a more specific description of the House of Relaxation and its features, see Serrano et al. (2013). 


\section{-INSERT FIGURE 1 AROUND HERE-}

\subsection{Hardware}

A PC computer with high-end graphic capabilities and an Intel Core 2 Quad processor was used. As navigation and interaction devices, a Wiimote remote control and a wireless receiver bar were used. The visual and audio displays consisted of a methacrylate screen (4x3 m), an HD video-projector with a resolution of $1280 \times 720$ pixels at 1400 lumens, and a 5.1 surround-sound system.

\subsection{Tactile and olfactory stimuli}

As the tactile stimulus, artificial grass measuring $2 \times 1 \mathrm{~m}$ was used. It was made of plastic and synthetic materials and had a thickness of $50 \mathrm{~mm}$. Its texture was thick and abundant, so that the tactile sensation was as similar to natural grass as possible.

As the olfactory stimulus, a lavender scent, distributed with a ceramic diffuser, a small-unscented candle and water, was used. The literature states that this scent tends to relax because it reduces arousal levels (Alaoui-Ismaili, Robin, Rada, Dittmar, \& Vernet-Mauri, 1997; Moss, Cook, Wesnes, \& Duckett, 2003). We used these "real" and "ecological" stimuli, which were consistent with objects that participants viewed in the House of Relaxation. In this way, there was an interaction between real and virtual objects, as both the artificial grass and the lavender scent enriched the VR environment and stimulated the senses of touch and smell. Figure 2 shows the experimental room and the tactile and olfactory stimuli.

\section{-INSERT FIGURE 2 AROUND HERE-}

\subsection{Design}

A between-groups factorial study with two evaluation moments (pre-test and post-test) and four experimental groups was used (see Figure 3): (1) VR (using only visual and hearing stimuli); (2) $V R-M I P+S m e l l$ (using visual, hearing, and tactile stimuli); (3) VR-MIP+Touch (using visual, 
hearing, and olfactory stimuli); (4) VR-MIP+Touch \& Smell (using visual, hearing, tactile, and olfactory stimuli). In all groups, a VR environment and MIPs were used. The senses of sight and hearing were stimulated in all groups. In addition, the senses of smell and/or touch were stimulated in three of the experimental groups.

\subsection{Procedure}

The experiment was performed in a VR-room with dimensions of $4.02 \times 4.77 \mathrm{~m}$. The length of each session was approximately $60 \mathrm{~min}$. As the purpose was to induce relaxation, anxiety and depression symptoms were assessed to keep these symptoms from acting as extraneous variables. The participants completed the pre-test VAS and SAM measures. Next, they were trained in the use of the navigation and interaction devices. The experiment was performed individually. At the beginning, participants listened to relaxing music; the initial appearance of the "House of Relaxation" was the same for all the groups, but participants were able to change it into a relaxing environment. During the experiment, a narrative with some instructions guided participants in doing different tasks in the "House of Relaxation". All the groups had to select affective pictures and relaxing self-statements and then watch a video with a relaxing scene. Only the groups where sense of touch was stimulated (VR_MIP+Touch and VR-MIP+Touch \& Smell) did a task where they had to touch the artificial grass while they were watching virtual grass; likewise, only the groups where the olfactory stimulus was used $(V R-M I P+S m e l l$ and $V R-M I P+T o u c h \&$ Smell $)$ did a task where they had to smell the lavender scent in the room while they were watching and interacting with a meadow in the VR environment and listening to sounds of nature. The narrative also guided participants in doing some customization tasks in the House of Relaxation (e.g., changing the furniture, changing the color of the walls, changing the floor into grass or sand, or changing the exterior landscape). Next, participants were asked to look at the relaxing environment and think about their personal meanings and how they were feeling. Finally, participants were asked to fill in 
the post-test VAS, SAM, and Presence-SAM measures. Figure 3 shows the procedure for each group.

\section{-INSERT FIGURE 3 AROUND HERE-}

\section{Results}

To evaluate the group's homogeneity before the relaxation induction, an Analysis of Variance (ANOVA) was applied with the pre-test VAS and SAM measures. No statistical differences were found among the four groups.

To test the first hypothesis, which predicted the efficacy of the VR-MIP for inducing relaxation, the results showed a significant increase in relaxation $[\mathrm{F}(1,132)=90.31, p<0.001]$ and a significant decrease in arousal $[\mathrm{F}(1,132)=92.04, p<0.001]$ after mood-induction. Other emotions also changed significantly: joy $[\mathrm{F}(1,132)=14.18, p<0.001]$ and affective valence $[\mathrm{F}(1,132)=8.65, p<0.01]$ increased; anxiety $[\mathrm{F}(1,132)=31.69, p<0.001]$ and sadness $[\mathrm{F}(1,132)=32.89, p<0.001]$ decreased; see Figure 4.

-INSERT FIGURE 4 AROUND HERE-

In order to test the second hypothesis, which predicted differences in relaxation between the groups after mood-induction, the results showed no statistical differences between the groups (Table 1). Post hoc tests indicated a higher level of relaxation and a lower level of arousal in all the groups.

\section{-INSERT TABLE 1 AROUND HERE-}

To test the third hypothesis, which predicted a high sense of presence after the VR-MIP, and the fourth hypothesis, which predicted statistical differences between groups, a one-way ANOVA was performed. No statistical differences were found between groups. Results showed that the sense of 
presence was high in all groups: $V R-M I P(M=5.87), V R-M I P+S m e l l(M=6.35), V R-M I P+T o u c h$ $(M=6.47), V R-M I P+T o u c h \&$ Smell $(M=6.35)$. Figure 5 shows the means between groups for the sense of presence.

\section{-INSERT FIGURE 5 AROUND HERE-}

\section{Discussion}

The main objectives of this study were to test, in a controlled study, the efficacy of a VR-MIP ("The Relaxation House") to induce relaxation and sense of presence, and to analyze whether the stimulation of the senses of touch and smell improves the efficacy of this VR-MIP for inducing relaxation and sense of presence. Data provide evidence supporting the first hypothesis, that is, the efficacy of this VR-MIP for inducing relaxation. After mood-induction, the relaxation level increased, and the arousal level decreased significantly; likewise, results show significant changes in other emotions (joy, affective valence, anxiety, and sadness). It is important to note two important aspects: (1) this study was carried out with a non-clinical sample, which means that the participants did not have any significant psychological problems related to anxiety and/or depression; (2) the relaxation level of participants before the mood-induction was high (see Table 1); this is an important aspect to consider because, although the initial relaxation average was high, the VR was able to increase it even more.

These results support other studies using VR-MIP (Baños et al., 2004a; 2004b; 2008; Baños et al., 2013; 2014; Herrero et al., 2014; Riva et al., 2007), and they confirm the data obtained in the previous pilot study using the "House of Relaxation" (Serrano et al., 2013), where positive moods increased while negative moods decreased. The results suggest that it is possible to induce different emotions in a controlled way using VR-MIP.

Data do not provide evidence supporting the second hypothesis about differences in relaxation between the experimental groups. The results show that all the groups had a high level of relaxation 
after mood-induction. Therefore, the stimulation of touch and/or smell does not appear to significantly improve the state of relaxation. Only a trend was observed: the groups whose sense of touch was stimulated seemed more relaxed.

Regarding the sense of presence, all the groups scored high on the illusion of being there in the VE, supporting our third hypothesis. This result agrees with other studies that also used VR-MIP to induce emotions and found a high sense of presence (Baños et al., 2004a; 2004b; 2008; Riva et al., 2007; Serrano et al., 2013). The data do not support the last hypothesis about differences in the sense of presence related to the stimulation of the senses of touch and smell. No statistical differences were found between groups. However, the results show a trend: in the groups where the sense of touch was stimulated, the sense of presence seems to increase. In addition, it is important to note that we measured the sense of presence using a pictorial scale that assesses only the personal and subjective factor of sense of presence (Presence-SAM (Schneider et al., 2004)), and this can influence the results for this variable.

This paper describes the first controlled study to analyze the effects of the stimulation of touch and smell in mood-induction and sense of presence. However, it should be noted that this study had some limitations. First, relaxation was the only emotion induced; in future studies it would be interesting to adapt this VR-MIP and test its efficacy in inducing other emotions (e.g., joy, hope, acceptance, admiration, optimism, etc.). Second, to stimulate the senses of touch and smell, artificial grass and lavender scent were used. These procedures are very simple and ecological, and they are noninvasive to the participant. However, they can make it difficult to control the variables, compared to the use of specific technological devices (olfactory or haptic devices) to stimulate these senses. Currently, some experimental studies in psychology are beginning to use these devices (Baus \& Bouchard, 2010; Rizzo et al., 2010; Tortell et al., 2007).

On the other hand, the technological devices that allow the stimulation of these senses using VR can be expensive and invasive, and many are not yet available commercially, for example, the system developed by Chalmers, Howard, and Moir (2009) to stimulate the five senses in a VE. Based on 
the above, we hypothesize that the use of technological devices could allow us to confirm the trend we have identified in relation to the role of the stimulation of touch in mood-induction and sense of presence. In addition, more conclusive data can be identified about the influence of olfactory stimulation on mood-induction and sense of presence.

\section{Conclusions}

The results of this study confirm that this VR-MIP ("House of Relaxation") is effective in inducing relaxation, and they show that it is possible to induce this emotion in a controlled way. Furthermore, the VR-MIP was also capable of generating high levels of sense of presence in participants. These results agree with previous studies that point out the utility of VR-MIP for inducing several emotions and moods (Baños et al., 2004a; 2004b; 2008; Baños et al., 2013; 2014; Herrero et al., 2014; Riva et al., 2007). These VR-MIP could have different applications, for example, as a tool for researching consumer behaviors (Serrano et al., 2013), in studies on emotional and experiential marketing, in designing products and services focused on users, or in museums or amusement parks (generating positive emotional experiences). In the future, VR-MIP could be integrated into our own homes or workplaces as a tool to help us in our daily lives (e.g., to be more relaxed or happier). In addition, VR-MIP could be a component of psychological treatments for different emotional problems (Aiken \& Berry, 2015; Baños et al., 2009; Baños et al., 2013; Beck et al., 1996; Carlin et al., 1997; Gross \& Levenson, 1995; Herrero et al., 2014).

Regarding the influence of stimulating touch and smell on mood-induction and generating a higher sense of presence; we hypothesized that the "additional stimulation" of these senses, especially the sense of touch, could improve the efficacy when using VR-MIP because it provides more sensory information. However, the data did not confirm this hypothesis. Emotions and sense of presence do not significantly improve when smell and/or touch were stimulated. Given the procedures used in this study to stimulate other senses, we cannot conclude that other augmented virtuality strategies 
(more or less sophisticated) are ineffective, only that the ones used in our study were not powerful enough or adequate. Clearly, further research is needed.

\section{References}

Aiken, M. P., \& Berry, M. J. (2015). Posttraumatic stress disorder: Possibilities for olfaction and virtual reality exposure therapy. Virtual Reality. doi: 10.1007/s10055-015-0260-x

Alaoui-Ismaili, O., Robin, O., Rada, H., Dittmar, A., \& Vernet-Mauri, E. (1997). Basic emotions evoked by odorants: Comparison between autonomic responses and self-evaluation. Physiology \& Behavior, 62(1), 713-720.

Baños, R., Botella, C., Liaño, V., Guerrero, B., Rey, B., \& Alcañiz, M. (2004a). Sense of presence in emotional virtual environments. Presence Teleoperators and Virtual Environment, 13(1), 156-159.

Baños, R. M., Botella, C., Alcañiz, M., Liaño, V., Guerrero, B., \& Rey, B. (2004b). Immersion and emotion:Their impact on the sense of presence. CyberPsychology \& Behavior, 7(6), 734741.

Baños, R. M., Botella, C., Guillen, V., García-Palacios, A., Quero, S., Bretón-López, J., \& Alcañiz, M. (2009). An adaptive display to treat stress-related disorders: EMMA's world. British Journal of Guidance and Counselling, 37(3), 347-356.

Baños, R. M., Botella, C., \& Perpiñá, C. (1999). Virtual reality and psychopathology. Cyberpsychology and Behavior, 2(4), 283-292.

Baños, R. M., Botella, C., Rubio, I., Quero, S., García-Palacios, A., \& Alcañiz, M. (2008). Presence and emotions in virtual environments: The influence of stereoscopy. [Research Support, Non-U.S. Gov't]. CyberPsychology \& Behavior, 11(1), 1-8. doi: 10.1089/cpb.2007.9936

Baños, R. M., Espinoza, M., García-Palacios, A., Cervera, J. M., Esquerdo, G., Barrajón, E., \& Botella, C. (2013). A positive psychological intervention using virtual reality for patients with advanced cancer in a hospital setting: A pilot study to assess feasibility. Supportive Care in Cancer, 21(1), 263-270. doi: 10.1007/s00520-012-1520-x 
Baños, R. M., Etchemendy, E., Farfallini, L., García-Palacios, A., Quero, S., \& Botella, C. (2014). EARTH of well-being system: A pilot study of an information and communication technology-based positive psychology intervention. Journal of Positive Psychology.

Baus, O., \& Bouchard, S. (2010). The sense of olfaction: Its characteristics and its possible applications in virtual environments. Journal of CyberTherapy and Rehabilitation, 3(1), 3150.

Beck, A. T., Steer, R. A., \& Brown, G. K. (1996). Manual for the BDI-II. San Antonio, TX: The Psychological Corporation.

Bradley, M. M., \& Lang, P. J. (1994). Measuring emotion: The self-assessment manikin and the semantic differential. Journal of Behavior Therapy and Experimental Psychiatry, 25(1), 4959.

Carlin, A. S., Hoffman, H. G., \& Weghorst, S. (1997). Virtual reality and tactile augmentation in the treatment of spider phobia: A case report. Behaviour Research and Therapy, 35(2), 153158.

Chalmers, A., Howard, D., \& Moir, C. (2009). Real Virtuality: A step change from virtual reality. Paper presented at the Proceedings - SCCG 2009: 25th Spring Conference on Computer Graphics.

Dinh, H. Q., Walker, N., Hodges, L. F., Song, C., \& Kobayashi, A. (1999). Evaluating the importance of multi-sensory input on memory and the sense of presence in virtual environments. Proceedings - Virtual Reality Annual International Symposium, 222-228.

Gross, J., \& Levenson, R. W. (1995). Emotion elicitation using films. Cognition and Emotion, 9(1), 87-108.

Herrero, R., García-Palacios, A., Castilla, D., Molinari, G., \& Botella, C. (2014). Virtual reality for the induction of positive emotions in the treatment of fibromyalgia: A pilot study over acceptability, satisfaction, and the effect of virtual reality on mood. Cyberpsychology, Behavior, and Social Networking, 17(6), 379-384. 
Hoffman, H. G., García-Palacios, A., Carlin, A., Furness, T. A., \& Botella, C. (2003). Interfaces that heal: Coupling real and virtual objects to treat spider phobia. International Journal of Human-Computer Interaction, 16(2), 283-300.

Hoffman, H. G., Hollander, A., Schroder, K., Rousseau, S., \& Furness, T. (1998). Physically touching and tasting virtual objects enhances the realism of virtual experiences. Virtual Reality, 3(4), 226-234.

Ito, T. A., Cacioppo, J. T., \& Lang, P. J. (1998). Eliciting affect using the international affective picture system: Trajectories through evaluative space. Personality and Social Psychology Bulletin, 24(8), 855-879.

Moltó, J., Montañez, S., Poy, R., Segarra, P., Pastor, M. C., Tormo, M. P., . . Vila, J. (1999). Un nuevo método para el estudio experimental de las emociones: el international affective picture system (IAPS). Adaptación española. Revista de Psicología General y Aplicada 52(1), 55-87.

Moss, M., Cook, J., Wesnes, K., \& Duckett, P. (2003). Aromas of rosemary and lavender essential oils differentially affect cognition and mood in healthy adults. International Journal of Neuroscience, 113(1), 15-38.

Riva, G., Mantovani, F., Capideville, C. S., Preziosa, A., Morganti, F., Villani, D., . . Alcañiz, M. (2007). Affective interactions using virtual reality: The link between presence and emotions. [Research Support, Non-U.S. Gov't]. CyberPsychology \& Behavior, 10(1), 45-56. doi: 10.1089/cpb.2006.9993

Rizzo, A., Difede, J., Rothbaum, B. O., Reger, G., Spitalnick, J., Cukor, J., \& McLay, R. (2010). Development and early evaluation of the virtual Iraq/Afghanistan exposure therapy system for combat-related PTSD. Annals of the NewYork Academy of Sciences, 1208, 114-125. doi: $10.1111 / \mathrm{j} .1749-6632.2010 .05755 . \mathrm{x}$

Rothbaum, B. O., Rizzo, A. S., \& Difede, J. (2010) Virtual reality exposure therapy for combatrelated posttraumatic stress disorder. Vol. 1208 (pp. 126-132). 
Saghaei, M. (2004). Random allocation software, from

http://mahmoodsaghaei.tripod.com/Softwares/randalloc.html

Sanz, J., Perdigón, L. A., \& Vázquez, C. (2003). Adaptación española del Inventario para la Depresión de Beck-II (BDI-II). Propiedades psicométricas en población general. Clínica y Salud, 14(3), 249-280.

Schneider, E. F., Lang, A., Shin, M., \& Bradley, S. D. (2004). Death with a story: How story impacts emotional, motivational, and physiological responses to first-person shooter video games. Human Communication Research, 30(3), 361-375.

Serrano, B., Botella, C., Baños, R. M., \& Alcañiz, M. (2013). Using virtual reality and moodinduction procedures to test products with consumers of ceramic tiles. Computers in Human Behavior, 29(3), 648-653. doi: 10.1016/j.chb.2012.10.024

Spielberger, C. D., Gorsuch, R. L., \& Lushene, R. E. (1986). Cuestionario de ansiedad estadorasgo: Manual (2 ed.). Madrid: TEA Ediciones.

Tortell, R., Luigi, D. P., Dozois, A., Bouchard, S., Morie, J. F., \& Ilan, D. (2007). The effects of scent and game play experience on memory of a virtual environment. Virtual Reality, 11(1), 61-68. doi: 10.1007/s10055-006-0056-0

Velten, E. (1968). A laboratory task for induction of mood states. Behaviour Research and Therapy, 6(4), 473-482.

Vila, J., Sánchez, M., Ramírez, I., Fernández, M. C., Cobos, P., Rodríguez, S., . . Moltó, J. (2001). El sistema Internacional de Imágenes Afectivas (IAPS): Adapatación española. Segunda parte. Revista de psicología. General y Aplicada, 54(4), 635-657.

Wewers, M. E., \& Lowe, N. K. (1990). A critical review of visual analogue scales in the measurement of clinical phenomena. Research in Nursing and Health, 13(4), 227-236.

Wissmath, B., Weibel, D., \& Mast, F. (2009). Measuring presence with verbal versus pictorial scales: A comparison between online- and ex post-ratings. Virtual Reality, 14(1), 43-53. 

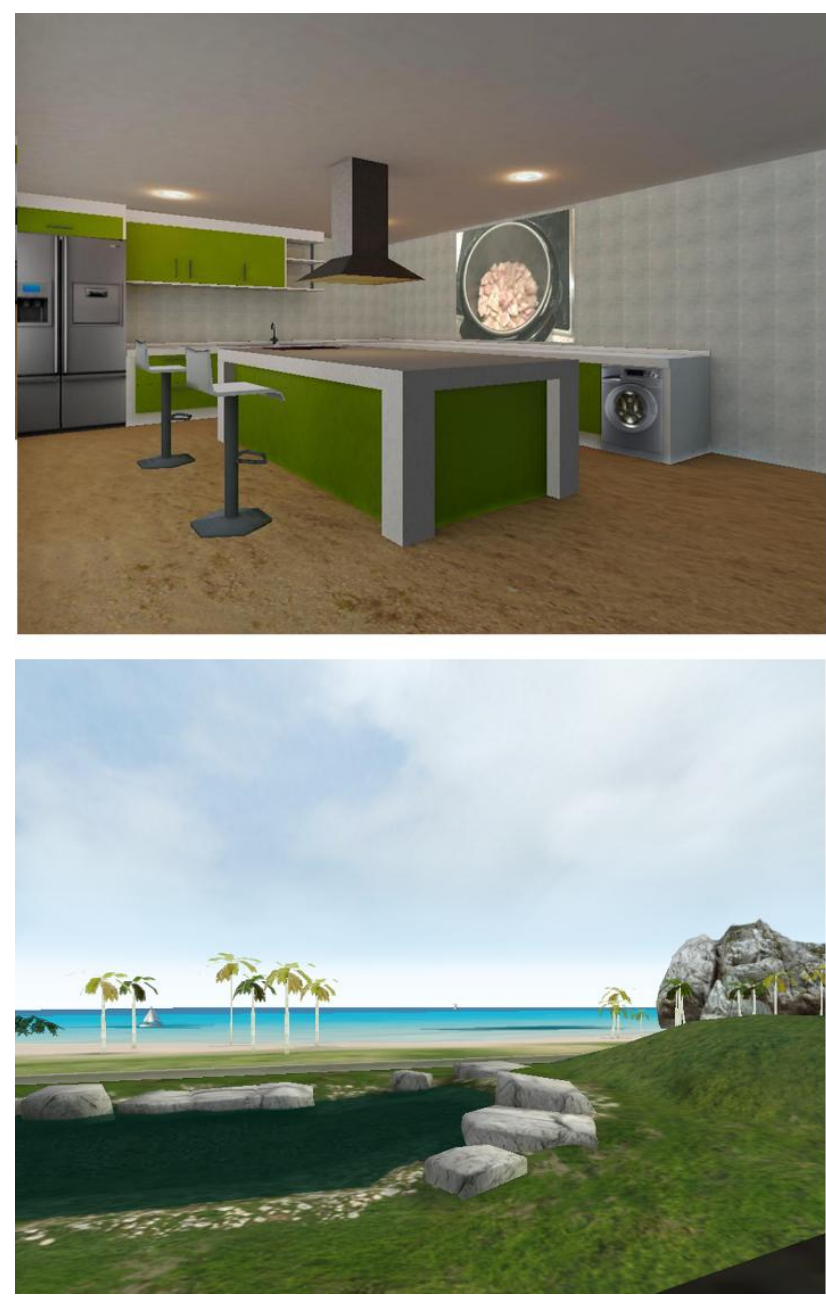

Figure 1. Virtual reality environment
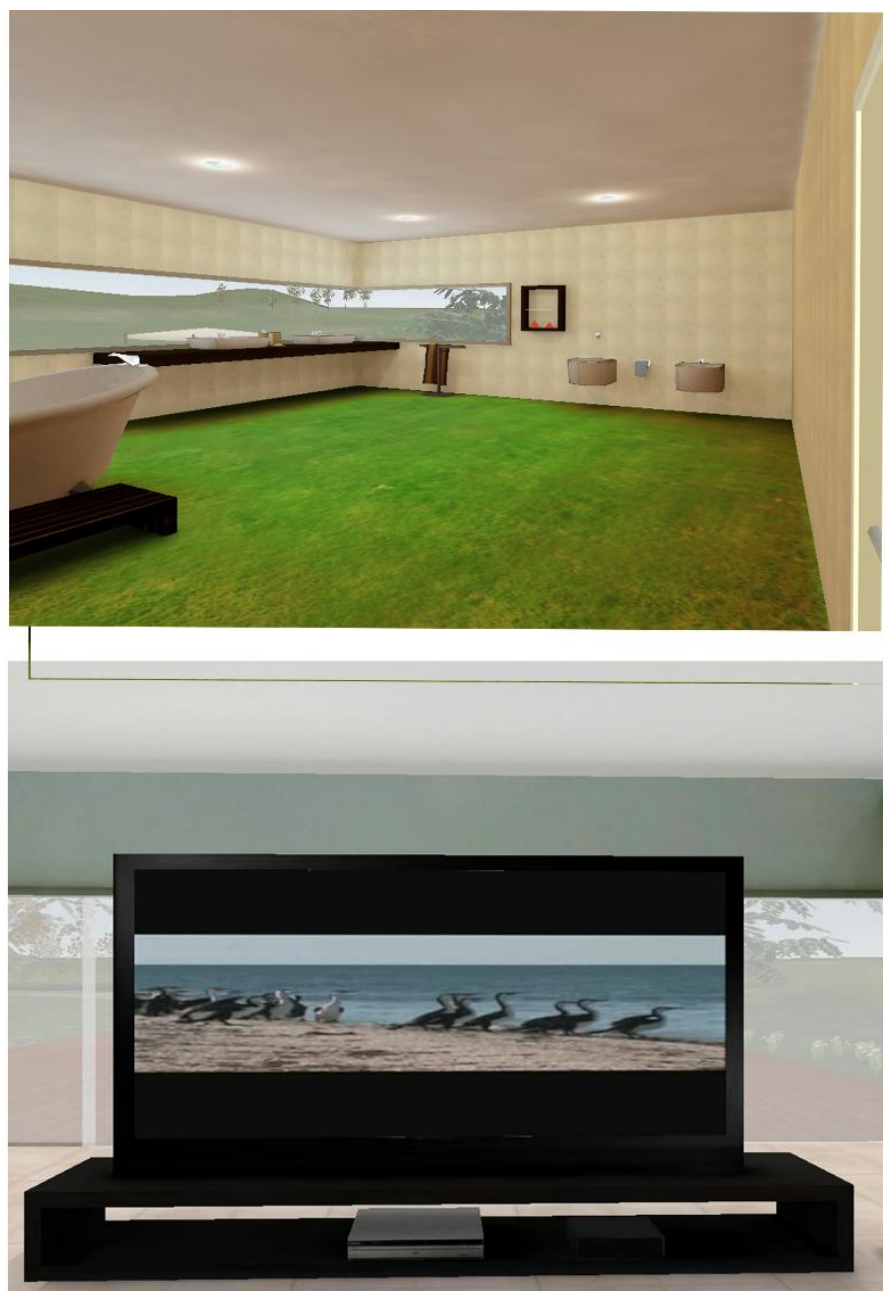

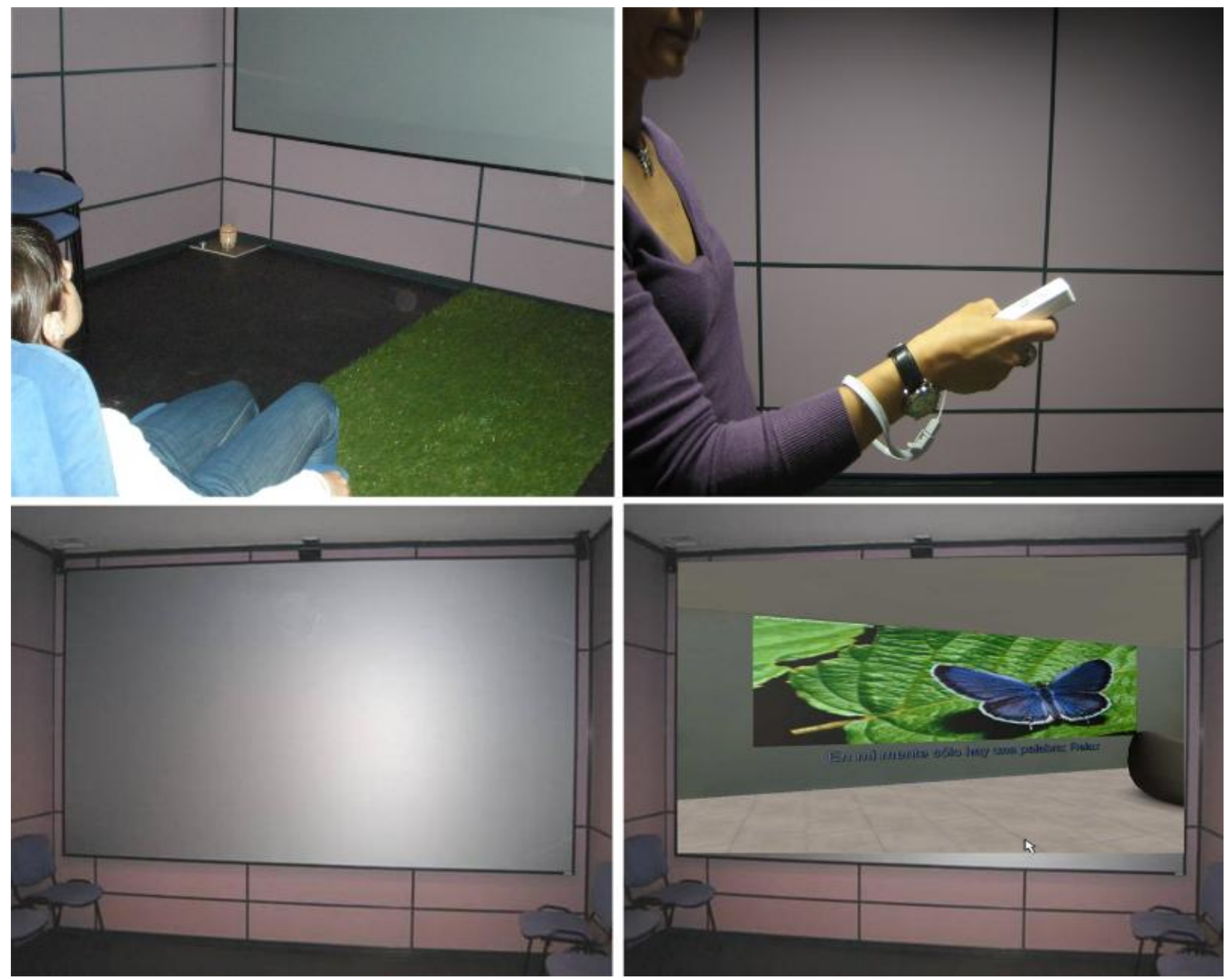

Figure 2. Experimental room, tactile, and olfactory stimuli 

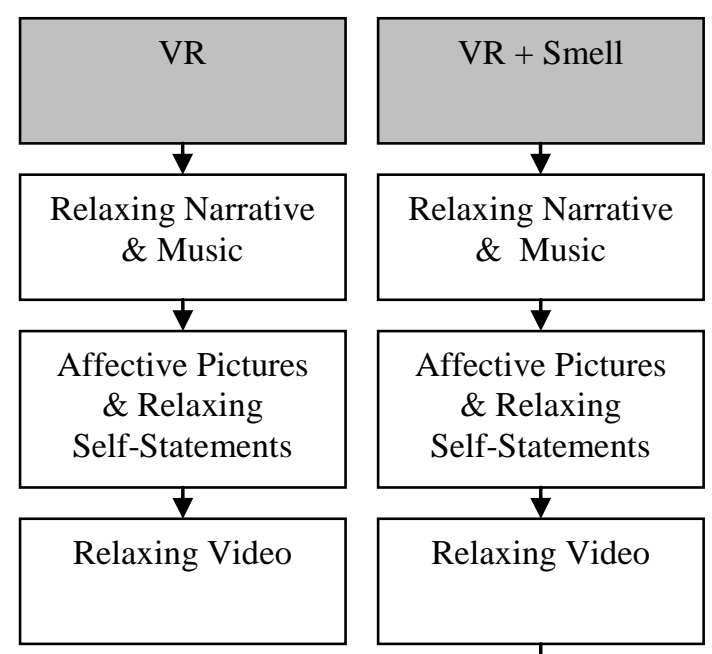

Relaxing Narrative \& Music
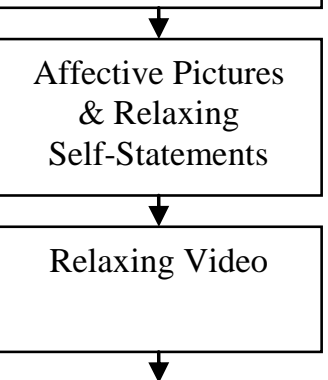

Smell the Lavender Scent \&

Listening to

Sounds of Nature
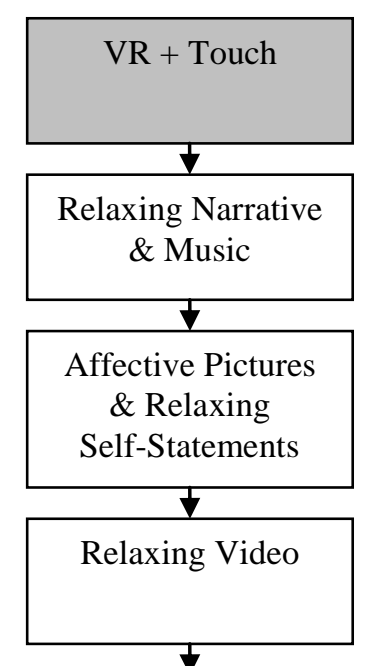

Touching the Artificial Grass \&

Listening to

Sounds of Nature

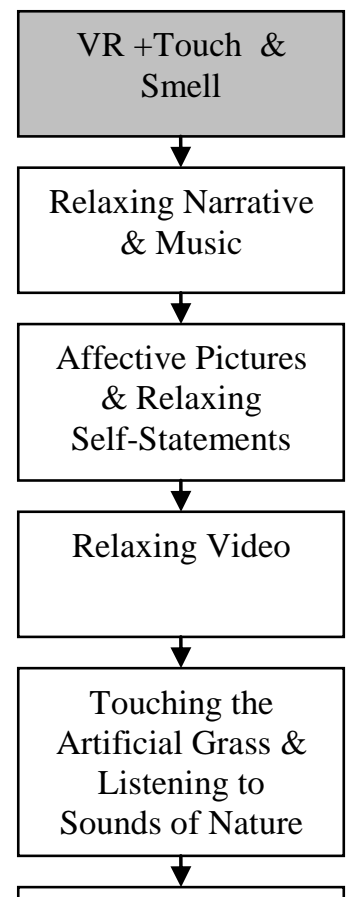

Smell the Lavender Scent \& Listening to Sounds of Nature

\section{Figure 3. Experimental procedure for each group}



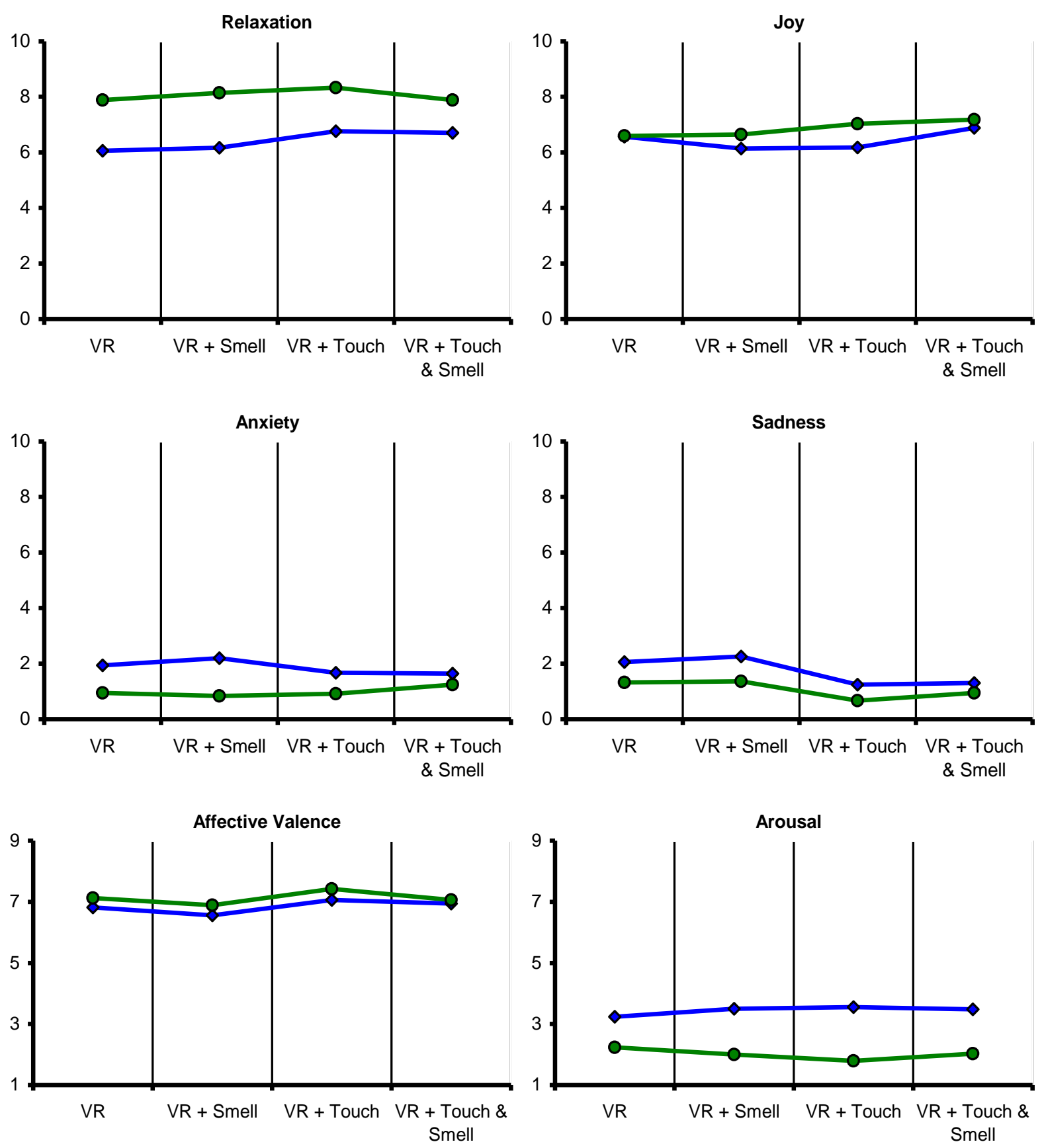

$\leadsto$ Pre-test $-0-$ Post-test

Figure 4. Means before and after mood-induction 
Table 1. Means and standard deviations of emotional variables in each group

\begin{tabular}{|c|c|c|c|}
\hline Variables & Groups* & Pre-test & Post-test \\
\hline Relaxation & $\begin{array}{l}\text { VR } \\
\text { VR + Smell } \\
\text { VR + Touch } \\
\text { VR + Touch \& } \\
\text { Smell }\end{array}$ & $\begin{array}{l}6.06(2.28) \\
6.17(2.23) \\
6.76(1.98) \\
6.70(2.22)\end{array}$ & $\begin{array}{l}7.78(1.75) \\
8.14(1.79) \\
8.33(1.68) \\
7.88(1.98)\end{array}$ \\
\hline , & $\begin{array}{l}\text { VR } \\
\text { VR + Smell } \\
\text { VR + Touch } \\
\text { VR + Touch \& } \\
\text { Smell }\end{array}$ & $\begin{array}{l}6.56(1.61) \\
6.14(1.65) \\
6.18(1.81) \\
6.88(1.76)\end{array}$ & $\begin{array}{l}6.59(1.79) \\
6.64(1.72) \\
7.03(1.42) \\
7.18(1.74)\end{array}$ \\
\hline Affective Valence & $\begin{array}{l}\text { VR } \\
\text { VR + Smell } \\
\text { VR + Touch } \\
\text { VR + Touch \& } \\
\text { Smell }\end{array}$ & $\begin{array}{l}6.82(0.90) \\
6.56(1.36) \\
7.06(1.17) \\
6.94(1.36)\end{array}$ & $\begin{array}{l}7.12(1.20) \\
6.89(1.34) \\
7.42(1.09) \\
7.06(1.17)\end{array}$ \\
\hline Arousal & $\begin{array}{l}\text { VR } \\
\text { VR + Smell } \\
\text { VR + Touch } \\
\text { VR + Touch \& } \\
\text { Smell }\end{array}$ & $\begin{array}{l}3.24(1.28) \\
3.50(1.54) \\
3.55(1.52) \\
3.48(1.66)\end{array}$ & $\begin{array}{l}2.24(1.47) \\
2.00(1.30) \\
1.79(1.49) \\
2.03(1.51)\end{array}$ \\
\hline Anxiety & $\begin{array}{l}\mathrm{VR} \\
\mathrm{VR}+\text { Smell }\end{array}$ & $\begin{array}{l}1.94(2.05) \\
2.19(2.42)\end{array}$ & $\begin{array}{l}0.94(0.91) \\
0.83(0.94)\end{array}$ \\
\hline
\end{tabular}




\begin{tabular}{|c|c|c|c|}
\hline & $\begin{array}{l}\text { VR + Touch } \\
\text { VR + Touch \& } \\
\text { Smell }\end{array}$ & $\mid \begin{array}{l}1.67(1.63) \\
1.64(2.16)\end{array}$ & 0.91 (1.56) \\
\hline Sadness & $\begin{array}{l}\text { VR } \\
\text { VR + Smell } \\
\text { VR + Touch } \\
\text { VR + Touch \& } \\
\text { Smell }\end{array}$ & $\begin{array}{l}2.06(1.93) \\
2.25(2.23) \\
1.24(1.32) \\
1.30(1.55)\end{array}$ & $\begin{array}{l}1.32(1.45) \\
1.36(1.55) \\
0.67(0.85) \\
0.94(1.36)\end{array}$ \\
\hline
\end{tabular}




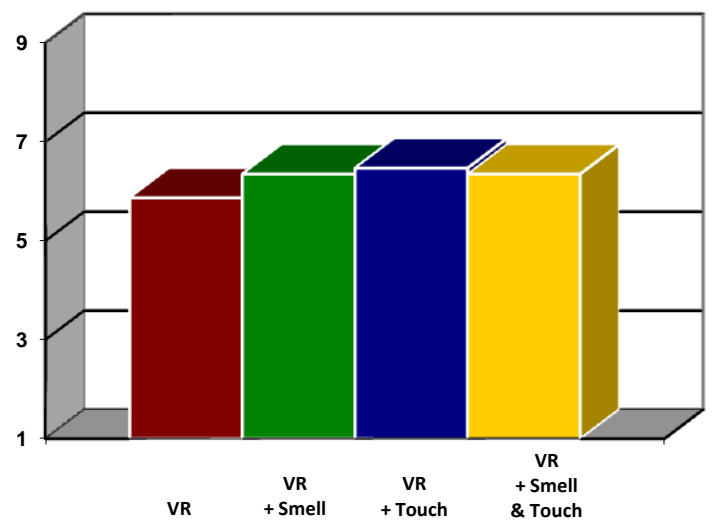

Figure 5. Means of sense of presence 